\title{
Epidemiological analysis and rapid detection by one-step multiplex PCR assay of Haemophilus influenzae in children with respiratory tract infections in Zhejiang Province, China
}

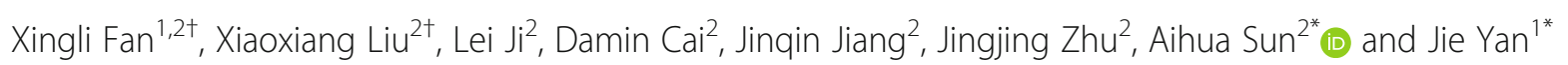

\begin{abstract}
Background: Haemophilus influenzae ( $H$. influenzae) is one of the most important pathogenic bacteria causing respiratory tract infection diseases in children. There are two main types of $\mathrm{H}$. influenzae, encapsulated $\mathrm{H}$. influenzae and nontypeable $H$. influenzae (NTHi). Serotype b of $H$. influenzae (Hib) used to be the main epidemic type of $H$. influenzae, causing the invasive infection. However, the epidemiology of invasive $H$. influenzae disease has changed substantially, and most invasive diseases are now caused by NTHi and other serotypes of $\mathrm{H}$. influenzae. The aim of this study was to determine the main epidemic strains of $\mathrm{H}$. influenzae in Zhejiang Province in China, and establish a one-step multiplex PCR assay to distinguish $\mathrm{H}$. influenzae from other bacteria associated with respiratory tract infections, and distinguish encapsulated $H$. influenzae from NTHi.
\end{abstract}

Method: In this study, bacterial culture and serum agglutination testing were used to determine the most prevalent serotype of $\mathrm{H}$. influenzae, and the results have served as a gold standard for clinical diagnosis. We also designed a one-step multiplex PCR assay using several kinds of standard strains of respiratory tract infection bacteria, to examine the stability, specificity, and detection limit of the PCR assays. We then used 1514 nasopharyngeal secretion (NPS) samples collected from children with respiratory tract infections to verify the specificity and sensitivity of the PCR assay.

Results: The bacterial culture and serum agglutination test results showed that the positive rates of $\mathrm{H}$. influenzae and encapsulated $H$. influenzae were 18.49 and $1.18 \%$, respectively. The PCR results showed that the detection limit of the multiplex PCR assay was $1.89 \times 10^{3}$ copies $/ \mu \mathrm{L}$, the ompP6 positive rate was $19.35 \%$, and the bexA positive rate was $1.32 \%$. The sensitivity and specificity of the multiplex PCR were 100 and $99.86 \%$, respectively.

Conclusions: According to our study, the most prevalent $H$. influenzae subtype in Zhejiang Province was NTHi, account for 93.57\%; the one-step multiplex PCR assay we established can be used as the differential detection of clinical H. influenzae strains, replacing routine bacterial culture and serum agglutination testing.

Keywords: Haemophilus influenzae, Respiratory tract infections, Epidemiological analysis, Multiplex PCR, Nontypeable H. influenzae, Encapsulated H. Influenzae

\footnotetext{
* Correspondence: aihuasun@126.com; med_bp@zju.edu.cn

${ }^{+}$Xingli Fan and Xiaoxiang Liu contributed equally to this work.

${ }^{2}$ Department of Basic Medicine, Hangzhou Medical College, Hangzhou

310058, Zhejiang, China

'Department of Medical Microbiology and Parasitology, Zhejiang University

School of Medicine, Hangzhou 310031, Zhejiang, China
}

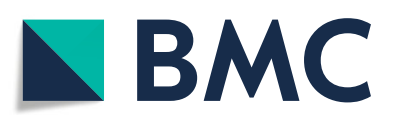

(c) The Author(s). 2018 Open Access This article is distributed under the terms of the Creative Commons Attribution 4.0 International License (http://creativecommons.org/licenses/by/4.0/), which permits unrestricted use, distribution, and reproduction in any medium, provided you give appropriate credit to the original author(s) and the source, provide a link to the Creative Commons license, and indicate if changes were made. The Creative Commons Public Domain Dedication waiver (http://creativecommons.org/publicdomain/zero/1.0/) applies to the data made available in this article, unless otherwise stated. 


\section{Background}

Haemophilus influenzae ( $H$. influenzae) is a Gram-negative coccobacillus that can cause invasive and severe infections, such as bacteria pneumonia, epiglottitis, sinusitis, and similar conditions, in both adults and children, especially in children under 5-years-old $[1,2]$. There are two main types of $H$. influenzae based on the capsule: encapsulated $H$. influenzae and nontypeable $H$. influenzae (NTHi). The NTHi cannot be typed by the serum agglutination test. Serotype b $H$. influenzae (Hib) used to be the main type of $H$. influenzae in respiratory tract infections, but the epidemiology of invasive $H$. influenzae disease has changed substantially, with most invasive diseases now caused by non-b serotypes and NTHi strains [3-8]. Different types of $H$. influenzae have different pathogeneses and require different treatments [9, 10]. Detection of $H$. influenzae by traditional methods like bacterial culture is cheap and facilitates the detection of antibiotic resistance. However, it is timeconsuming and may give false-negative results during ongoing antibiotic treatment. Serum agglutination testing was widely used to determine the serotype of encapsulated $H$. influenzae, and it can also be used to discriminate the encapsulated $H$. influenzae from NTHi. However, sometimes there are bacterial self-coagulation phenomena and cross agglutination, and serological reagents are more expensive.

Because the specificity of PCR depends on the selection of target genes, it is challenging to design a specific PCR test for the detection of $H$. influenzae and discriminate encapsulated $H$. influenzae from NTHi. The gene ompP6, which encodes the outer membrane protein P6, is present in all the $H$. influenzae strains and has a highly conserved nucleotide sequence. The nucleotide sequence homology of ompP6 was $96.7-100 \%$. OmpP6 is a good target gene to distinguish $H$. influenzae from other respiratory tract infection bacteria [11-13]. The gene bex $A$ encoding the capsule transport protein exists only in encapsulated $H$. influenzae, and the nucleotide sequence at site 3552-3865 is highly conserved [14-17]. According to the distribution and sequence of ompP6 and bexA, we designed two pairs of primers to establish a one-step multiplex PCR assay for differential detection of clinical $H$. influenzae species from nasopharyngeal secretion (NPS) in patients with respiratory tract infections in order to improve the detection rate and identify the predominant $H$. influenzae strain in Zhejiang Province in China.

\section{Methods}

\section{Subjects}

This work has obtained the approval from the Research Ethics Committee of Hangzhou Medical College. The approval numbers are 2012-001.The nasopharyngeal secretion (NPS) used in this study have been allowed to collect from patients with respiratory tract infections. Written informed consents have been obtained from the participants.

One thousand five hundred fourteen NPSs were gathered from patients diagnosed with respiratory tract infection disease and treated in the Yiwu Women and Children's Hospital and the Shaoxing City Keqiao District Hospital of Traditional Chinese Medicine from 2012 to 2016. They all diagnosed with respiratory tract infection, including 289 sinusitis, 108 bronchitis, 83 bronchopneumonia, 262 tonsilitis, 53 HFMD, 133 herpangina, 80 stomatitis, 80 submaxillary lymphadenitis and 426 other respiratory tract diseases. The patients ranged from 0 to 14 years old, and included 825 boys and 689 girls. One thousand fifty-five of them were 5 or under 5 years old, 459 of them were 6 or elder than 6 . No antibiotics were used in the $72 \mathrm{~h}$ preceding admission. Under nasal endoscopy, nasal meatus secretions were obtained by cotton swabs from these patients, placed in sterile tubes, and immediately sent to the laboratory for pathogen isolation. The same amount of $\mathrm{pH} 7.61 \%$ trypsin was added to the samples and incubated for $90 \mathrm{~min}$ at $37{ }^{\circ} \mathrm{C}$ to homogenize the NPSs, and $200 \mu \mathrm{L}$ of the homogenized sample was used for bacterial culture. The remains were kept at $-80{ }^{\circ} \mathrm{C}$.

\section{Bacterial culture and identification}

Here, $100 \mu \mathrm{L}$ of each homogenized sample was inoculated on blood plates and chocolate plates under sterile conditions by zoning streak and incubated in $5 \% \mathrm{CO}_{2}$ incubators at $37{ }^{\circ} \mathrm{C}$ for $24-48 \mathrm{~h}$. The $H$. influenzae was screened preliminarily by colony morphology of and the characteristics of Gram staining, and then identified by $\mathrm{V}$ factor, $\mathrm{X}$ factor and $\mathrm{V}+\mathrm{X}$ factors requirement test. NTHi ATCC49247, encapsulated H. influenzae standard strain ATCC 9327 (Type a), ATCC 9334 (Type b), ATCC 9007 (Type c), ATCC 9332 (Type d), ATCC 8142 (Type e) and ATCC 9833 (Type f), Streptococcus pneumoniae ATCC 49619, Staphylococcus aureus ATCC 29213, Klebsiella pneumoniae ATCC 700603, Pseudomonas aeruginosa ATCC 27853, E. coli ATCC 25922 were donated by department of pathogenic biology, Zhejiang University. The standard $H$. influenzae strains were cultured with selective medium and other standard strains were cultured on blood plates, in $5 \% \mathrm{CO}_{2}$ incubators at $37^{\circ} \mathrm{C}$ for $24-48 \mathrm{~h}$.

\section{Serum agglutination test}

The antisera of serotypes a, b, c, d, e, and $\mathrm{f}$ of $H$. influenzae were used to determine the serotype of $H$. influenzae, which we cultured from clinical samples using a slide agglutination test. Serotyping reagents were purchased from TBC in the United States (batch number: IM-H1015). 


\section{DNA extraction}

The fresh cultures of each standard strain were centrifuged after saline washing, and genomic DNA was extracted by using a Bacterial Genomic DNA Extraction Kit (GENEray). DNA from homogenized samples was also extracted using the same kit. The concentration and purity of DNA were determined by UV spectrophotometry.

\section{One-step multiple PCR assay design}

In this PCR assay, we designed two sets of primers of ompP6 and bexA according to the nucleotide sequence of $H$. influenzae type b reported on GenBank (Table 1). The expected ompP6 amplified product was the whole 459 bp sequence of ompP6 and the expected bexA amplified product was about $343 \mathrm{bp}$, only the conserved region at 3552-3895 site of bexA gene. All primers were purchased from Thermo Fisher Scientific, Inc. (China). The DNAs of NTHi standard strain ATCC49247, encapsulated $H$. influenzae standard strain ATCC 9327 (Type a), ATCC 9334 (Type b), ATCC 9007 (Type c), ATCC 9332 (Type d), ATCC 8142 (Type e), and ATCC 9833 (Type f), Streptococcus pneumoniae ATCC 49619, Staphylococcus aureus ATCC 29213, Klebsiella pneumoniae ATCC 700603, Pseudomonas aeruginosa ATCC 27853, and E. coli ATCC 25922 were used to develop the PCR assay. The PCR amplification was performed in $50 \mu \mathrm{L}$ reactions containing: $2.5 \mathrm{~mol} / \mathrm{L}$ of dNTP, $250 \mathrm{~mol} / \mathrm{L}$ of each primer, $2.5 \mathrm{U}$ of Ex-Taq DNA polymerase (Takara), $2 \mu \mathrm{L}$ target DNA and $1 \times$ PCR buffer. The PCR cycler was set to the following program: 4 min of enzyme activation at $94{ }^{\circ} \mathrm{C}$, followed 35 cycles at $94{ }^{\circ} \mathrm{C}$ for $30 \mathrm{~s}$, and $54{ }^{\circ} \mathrm{C}$ for $30 \mathrm{~s}$ and $72{ }^{\circ} \mathrm{C}$ for $45 \mathrm{~s}$, followed by 1 cycle at $72{ }^{\circ} \mathrm{C}$ for $5 \mathrm{in}$. The PCR product was examined by $2 \%$ agarose electrophoresis.

\section{Repeatability and specificity of the PCR assay}

The PCR were repeated three times under the same conditions. The PCR amplification of ompP6 and bexA of standard strains were purified using a PCR product purification kit and then sequenced by Thermo Fisher Scientific, Inc. All the sequenced nucleotide sequences were compared using the sequence reported on GenBank.

\section{Detection limit of PCR assay}

$H$. influenzae standard strain ATCC 9334 (type b) was used to determine the detection limit of the ompP6 PCR assay and multiplex PCR assay. The DNA concentration

Table 1 One-step multiple PCR primers

\begin{tabular}{ll}
\hline Oligonucleotide & Sequence \\
\hline ompP6 forward & 5'-ATGAACAAATTTGTAAATCA-3' \\
ompP6 reverse & 5'-TGCGATGTTGTATTCAGGTGTA-3' \\
bexA forward & 5'-CGTTTGATGATGTTGATCCA-3' \\
bexA reverse & 5'-TGTCCATGTCTTCAAAATG-3' \\
\hline
\end{tabular}

of ATCC 9334 was diluted 10 times and added to the PCR reaction. The DNA concentration was $1.89 \times 10^{6}$ copies/ $\mu \mathrm{L}, 1.89 \times 10^{5}$ copies $/ \mu \mathrm{L}, 1.89 \times 10^{4}$ copies $/ \mu \mathrm{L}, 1.89 \times 10^{3}$ copies $/ \mu \mathrm{L}$, and $1.89 \times 10^{2}$ copies $/ \mu \mathrm{L}$, respectively. The lowest DNA concentration at which positive products could be amplified was considered the detection limit.

\section{Determination of $H$. influenzae in clinical samples by the multiplex PCR}

We used the multiplex PCR assays we established to detect the $H$. influenzae subtype of the 1514 clinical NPSs.

\section{Statistical analysis}

Statistical analysis was performed using IBM SPSS Statistics ver. 11.0 (IBM Co., Armonk, NY, USA). Statistical significance was defined as $P<0.05$. Chi-square test was used in this study. The sensitivity and specificity of the multiplex were measured by comparison to the results of bacterial culture and serum agglutination.

\section{Results}

Bacterial culture results of 1514 NPSs from children with respiratory tract infections

Of 1514 NPSs from children with respiratory tract infection, 280 were positive for $H$. influenzae as indicated by bacteria culture, the positive ratio was $18.49 \%$. The $H$. influenzae infection rates of boys and girls with respiratory tract infectious diseases were 20\% (165/825) and $16.69 \%(115 / 689)$, and there was no significant difference in infection rate between boys and girls $\left(\chi^{2}=1.2\right.$, $P>$.05) (Table 2).

\section{Results of serum agglutination test of $\mathrm{H}$. influenzae}

According to the serum agglutination test, there were $262 \mathrm{NTHi}$ strains among all $280 \mathrm{H}$. influenzae strains cultured from NPSs, accounting for $93.57 \%$. There were 18 strains of encapsulated $H$. influenzae, including 4 type a, 1 type b, 4 type c and 9 type $\mathrm{f}$ (Table 2).

Specificity, stability, and detection limit of the PCR assay All the $H$. influenzae standard strains had amplification of ompP6 and the standard strains of Staphylococcus aureus, Streptococcus pneumoniae, Klebsiella pneumoniae, E.coli, and Pseudomonas aeruginosa showed negative results in the multiplex PCR assays. The encapsulated $H$. influenzae determined by serological test had amplification products of bexA. The PCR was performed in triplicate at different times and the same results were found. The results obtained here matched the ompP6 and $\operatorname{bex} A$ nucleotide sequences reported on the GenBank. The detection limit of the multiplex PCR assay we used was $1.89 \times 10^{3}$ copies $/ \mu \mathrm{L}$. 
Table 2 Results of bacterial culture and serum agglutination test

\begin{tabular}{lllllll}
\hline Bacterial culture & H. influenza-positive & & & H. influenza-negative & Total cases \\
\hline Serotype & NTHi & Serotype a & Serotype b & Serotype c & Serotype f & 1234 \\
& 262 & 4 & 1 & 4 & 9 & 1514 \\
Total cases & & & 280 & & & 9 \\
\hline
\end{tabular}

\section{$H$. influenzae detection in nasopharyngeal secretions (NPSs) with one-step multiple PCR assay}

Two hundred seventy-three of 1514 NPSs were found to be positive only ompP6 positive and 20 of 1514 were found to be positive for both ompP6 and bexA when assessed using the multiplex PCR scenario established above. The sensitivity and specificity of the multiplex PCR were 100 and 99.86\%, respectively (Table 3).

\section{Discussion}

H. influenzae is a common pathogen, causing acute respiratory tract infection and meningitis in children in most developing countries [18]. The epidemiology of invasive $H$. influenzae disease has changed substantially, with most invasive diseases now caused by non-b serotypes and NTHi strains [3-8].The incidence of infectious disease caused by Hib declined and that caused by other serotypes of $H$. influenzae and NTHi has increased over the past 10 years [4-7], especially in Europe and North America. NTHi caused $78 \%$ of all cases and showed increasing trends among persons $<1$ month and $>20$ years of age in Europe. Establishing the contribution of NTHi to respiratory tract infections may be helpful in the development of a new vaccine against NTHi that outweighs the cost of long-term healthcare in terms of repeated episodes and sequelae.

Drug resistance of bacteria is a serious problem. $\beta$-lactamase production in $H$. influenzae and NTHi is still the dominant resistance mechanism against $\beta$-lactams. The prevalence of $\beta$-lactamase in NTHi differs widely worldwide, strains with $\beta$-lactamase independent resistance to $\beta$-lactams have emerged and are spreading. The emergence and spread of $\beta$-lactamase-negative ampicillin-resistant strains in many regions of the world is of substantial concern, potentially necessitating changes to antibiotic treatment guidelines for community-acquired infections of the upper and lower respiratory tract and potentially increasing morbidity associated with invasive NTHi infections [19].

In recent years, the predominant strains of $H$. influenzae have varied across different regions of China, and the distribution of dominant strains in one place has also been affected by disease type, patient age, and similar factors. It is very important to quickly and accurately distinguish $H$. influenzae from other bacteria, or encapsulated $H$. influenzae from NTHi for timely treatment.

Zhejiang is a major economic province in China, located in southeastern China with a large population. In this study, we gathered 1514 NPSs and used traditional detection methods to determine the $H$. influenzae infection ratio and serotype of $H$. influenzae in Zhejiang Province in China. According to results of the bacterial culture and serum agglutination test, the $H$. influenzae infection rate in respiratory tract infections in children ranged from 0 to 14 years was $18.48 \%$ (280/1514), of all the $H$. influenzae we detected from clinical samples, 93.57\% (262/280) belonged to NTHi, only 6.43\% (18/ 2280 ) were encapsulated $H$. influenzae, and only $0.36 \%$ were Hib. It means NTHi is the predominant strain of $H$. influenza in children respiratory tract infection in Zhejiang province, China.

Because $H$. influenzae is a fastidious bacterium, the rate of detection of $H$. influenzae with routine bacterial culture is low. Serum agglutination tests have become widely used to determine the serotype of encapsulated $H$. influenzae. But sometimes there are bacterial self-coagulation phenomena and cross agglutination, and serological reagents are more expensive. In recent years, PCR has become widely used to detect pathogenic microorganisms in different samples, especially bacteria which are difficult to culture under routine conditions.

Table 3 Comparison of one-step multiple PCR and bacterial culture plus serum agglutination test of 1514 NPS

\begin{tabular}{|c|c|c|c|c|c|}
\hline \multirow[t]{3}{*}{ Item } & \multicolumn{3}{|c|}{ bacterial culture + serum agglutination test } & \multirow{3}{*}{$\begin{array}{l}\text { Specificity } \\
(\%)\end{array}$} & \multirow{3}{*}{$\begin{array}{l}\text { Sensitivity } \\
(\%)\end{array}$} \\
\hline & \multicolumn{2}{|c|}{ H. influenzae-positive } & \multirow{2}{*}{$\begin{array}{l}\mathrm{H} . \\
\text { influenzae- } \\
\text { negative }\end{array}$} & & \\
\hline & NTHi & Encapsulated $\mathrm{H}$. influenzae & & & \\
\hline ompP6+, bexA + & 2 & 18 & 0 & 99.86 & 100 \\
\hline ompP6+, bexA - & 260 & 0 & 13 & & \\
\hline ompP6-, bexA - & 0 & 0 & 1221 & & \\
\hline Total & & 1514 & & & \\
\hline
\end{tabular}


Considering of these, we also established a one-step multiple PCR assay by detecting the ompP6 and bexA genes, and we used several kinds of standard strains of respiratory tract infection bacteria, including $\mathrm{H}$. influenza, to examine the stability, specificity, and detection limit of the PCR assay. The results showed that the PCR assay had high stability and specificity, and the detection limit of the PCR assay was $1.89 \times 103$ copies $/ \mu \mathrm{L}$. The 1514 NPSs were used to verify the specificity and sensitivity of the PCR assay. In this study, 293 of 1514 NPSs were ompP6- positive, the detection rate of $\mathrm{H}$. influenzae was $19.35 \%$ (293/1514). The $H$. influenzae positive rate of one-step multiple PCR is higher than bacterial culture, it's the reason why we want detect $H$. influenzae by PCR instead of bacterial culture because $H$. influen$z a e$ is a fastidious bacterium and maybe there are some false negative.

Twenty of 1514 NPSs were bexA gene-positive, and the positive rate was $1.32 \%$, compared with the serum agglutination test, 2 NTHi were missed diagnosed. It may be a new finding, and it may be the key note for further researches in PCR and molecular characterization.

Compared with the results of bacterial culture and the serum agglutination test, the sensitivities of ompP6 and bexA detection were both $100 \%$, and the specificity of the multiplex PCR was $99.86 \%$. There was no significant difference in the rate of detection of $H$. influenzae between the multiplex PCR and the routine bacterial culture (18.49\%).

According to our study, and considering the shortages of bacterial culture and serum agglutination test, the one-step multiplex PCR assay we established can be used to identify encapsulated $H$. influenzae and NTHi in place of routine bacterial culture and serum agglutination testing, but it cannot be used to determine the serotype of encapsulated $H$. influenzae. It is necessary to design new, effective, specific typing primers, which will require further research.

\section{Conclusions}

According to our study, the infection rate of $\mathrm{H}$. influenzae in respiratory tract infections was $18.49 \%$; the most prevalent subtype of $H$. influenzae in Zhejiang Province was NTHi, account for $93.57 \%$; the sensitivity and specificity of the one-step multiplex PCR assay we established were 100 and $99.86 \%$, respectively; the multiplex PCR can be used as the differential detection of clinical $H$. influenzae strains, replacing the routine bacterial culture and serum agglutination testing.

\section{Abbreviations}

$H$. influenzae: Haemophilus influenzae; HFMD: hand foot mouth disease: NPS: nasopharyngeal secretion; NTHi: nontypeable Haemophilus influenzae

\section{Acknowledgements}

The authors would like to thank the Yiwu Women and Children's Hospital and the Shaoxing City Keqiao District Hospital of Traditional Chinese Medicine for their support in this study.

\section{Funding}

This work was supported by Zhejiang Provincial Program for the Cultivation of High-level Innovative Health talents, the General Research Project of the Zhejiang Provincial Education Department (No:: Y201738453) and the National Natural Science Foundation of China (No:: 81772232). The funding bodies had no role in the design of the study, collection, analysis, and interpretation of data and in writing the manuscript.

\section{Availability of data and materials}

The data and material generated and analyzed during the current study are not publicly available due to the protection of privacy but are available from the corresponding author on reasonable request.

\section{Authors' contributions}

$X L F$ and $X X L$ were responsible for the initial study concept and PCR detection. JY and AHS all contributed to the study design and experimental guidance. DMC carried out the data and patients collection, JQJ and $\amalg J$ were responsible for bacterial culture and serological tests. All the statistical analysis was finished by JJZ. All authors read and approved the final manuscript.

\section{Ethics approval and consent to participate}

This work has obtained the approval from the Research Ethics Committee of Hangzhou Medical College. The approval numbers are 2012-001.The nasopharyngeal secretion (NPS) used in this study have been allowed to collect from patients with respiratory tract infections. Written informed consents have been obtained from the participants. We also have obtained the written informed consents from the guardians on behalf of the minors/ children enrolled in our study.

\section{Consent for publication}

Not applicable.

\section{Competing interests}

The authors declare that they have no competing interests.

\section{Publisher's Note}

Springer Nature remains neutral with regard to jurisdictional claims in published maps and institutional affiliations.

Received: 7 February 2018 Accepted: 1 August 2018

Published online: 22 August 2018

\section{References}

1. Jalalvand F, Riesbeck K. Haemophilus influenzae: recent advances in the understanding of molecular pathogenesis and polymicrobial infections. Curr Opin Infect Dis. 2014;27:268-74

2. Falade AG, Ayede Al. Epidemiology, aetiology and management of childhood acute community-acquired pneumonia in developing countries-a review. Afr J Med Med Sci. 2011:40:293-308.

3. Resman F, Ristovski M, Ahl J, Forsgren A, Gilsdorf JR, Jasir A, Kaijser B, Kronvall G, Riesbeck K. Invasive disease caused by Haemophilus influenzae in Sweden 1997-2009; evidence of increasing incidence and clinical burden of non-type b strains. Clin Microbiol Infect. 2011;17(11):1638-45.

4. Urwin G, Krohn JA, Deaver-Robinson K, Wenger JD, Farley MM. Invasive disease due to Haemophilus influenzae serotype of clinical and epidemiologic characteristics in the $H$. influenzae serotype b vaccine era. The Haemophilus influenzae study group. Clin Infect Dis. 1996;22:1069-76.

5. Tsang RS, Sill ML, Skinner SJ, Law DK, Zhou J, Wylie J. Characterization of invasive Haemophilus influenzae disease in Manitoba, Canada, 2000-2006: invasive disease due to non-type b strains. Clin Infect Dis. 2007:44:1611-4.

6. Brown VM, Madden S, Kelly L, Jamieson FB, Tsang RSW, Ulanova M. Invasive Haemophilus influenzae disease caused by non-type b strains in Northwestern Ontario, Canada, 2002-2008. Clin Infect Dis. 2009;49:1240-3.

7. Whittaker R, Economopoulou A, Dias JG, Bancroft E, Ramliden M, Celentano $L P$, European Centre for Disease Prevention and Control Country Experts for 
Invasive Haemophilus influenzae Disease. Epidemiology of invasive Haemophilus influenzae disease, Europe 2007-2014. Emerg Infect Dis. 2017; 23:396-404.

8. Van Eldere J, Slack MPE, Ladhani S, Cripps A. Non-typeable Haemophilus influenzae, an under-recognized pathogen. Lancet Infect Dis. 2014;14:1281-92.

9. Lichtenegger S, Bina I, Durakovic S, Glaser P, Tutz S, Schild S, Reidl J. Serum resistance and phase variation of a nasopharyngeal non-typeable Haemophilus influenzae isolate. Int J Med Microbiol. 2017;307:139-46.

10. Dabernat H, Delmas C. Epidemiology and evolution of antibiotic resistance of Haemophilus influenzae in children 5 years of age or less in France, 2001-2008: a retrospective database analysis. Eur J Clin Microbiol Infect Dis. 2012;31:2745-53.

11. Murphy TF, Kirkham C, Lesse AJ. Construction of a mutant and characterization of the role of the vaccine antigen P6 in outer membrane integrity of nontypeable Haemophilus influenzae. Infect Immun. 2006;74(9):5169-76.

12. Sabirov A, Casey JR, Murphy TF, Pichichero ME. Breastfeeding is associated with a reduced frequency of acute otitis media and high serum antibody levels against NTHi and outer membrane protein vaccine antigen candidate P6. Pediatr Res. 2009;65(5):565-70.

13. Abdeldaim GM, Stalin K, Kirsebom LA, Olcen P, Blomberg J, Herrmann B. Detection of Haemophilus influenzae in respiratory secretions from pneumonia patients by quantitative real-time polymerase chain reaction. Diagn Microbiol Infect Dis. 2009;64(4):366-73.

14. Corless CE, Guiver M, Borrow R, Edwards-Jones V, Fox AJ, Kaczmarski EB. Simultaneous detection of Neisseria meningitidis, Haemophilus influenzae, and Streptococcus pneumoniae in suspected cases of meningitis and septicemia using real-time PCR. J Clin Microbiol. 2001;39:1553-8.

15. Satola SW, Schirmer PL, Farley MM. Genetic analysis of the capsule locus of Haemophilus influenzae serotype. Infect Immun. 2003;71:7202-7.

16. Zhou J, Law DK, Sill ML, Tsang RS. Nucleotide sequence diversity of the bexA gene in serotypeable Haemophilus influenzae strains recovered from invasive disease patients in Canada. J Clin Microbiol. 2007;45:1996-9.

17. Law DK, Tsang RS. Real-time polymerase chain reaction for detection of encapsulated Haemophilus influenzaeusing degenerate primers to target the capsule transport gene bexA. Can J Microbiol. 2013:59:359-61.

18. Casey RM, Dumolard L, Danovaro-Holliday MC, Gacic-Dobo M, Diallo MS, Hampton LM, Wallace AS. Global routine vaccination coverage, 2015. MMWR Morb Mortal Wkly Rep. 2016;65:1270-3.

19. Kakuta R, Yano H, Hidaka H, Kanamori H, Endo S, Ichimura S, Ogawa M, Shimojima M, Ozawa D, Inomata S, Tanouchi A, Kaku M, Katori Y. Molecular epidemiology of ampicillin-resistant Haemophilus influenzae causing acute otitis media in Japanese infants and young children. Pediatr Infect Dis J. 2016;35:501-6. doi: https://doi.org/10.1097//NF.0000000000001066.

Ready to submit your research? Choose BMC and benefit from:

- fast, convenient online submission

- thorough peer review by experienced researchers in your field

- rapid publication on acceptance

- support for research data, including large and complex data types

- gold Open Access which fosters wider collaboration and increased citations

- maximum visibility for your research: over $100 \mathrm{M}$ website views per year

At $\mathrm{BMC}$, research is always in progress.

Learn more biomedcentral.com/submissions 